H I S T O R I A M Í N I M A S

\title{
Repartiendo responsabilidades
}

\section{Distributing responsibilities}

Cristóbal Gómez Mayorga *

Recibido: 30 de septiembre de 2021 Aceptado: 29 de noviembre de 2021 Publicado: 31 de enero de 2022

To cite this article: Gómez Mayorga, C. (2022). Repartiendo responsabilidades. Márgenes, Revista de Educación de la Universidad de Málaga, 3(1), 139-141

DOI: http://dx.doi.org/10.24310/mgnmar.v3i1.13599

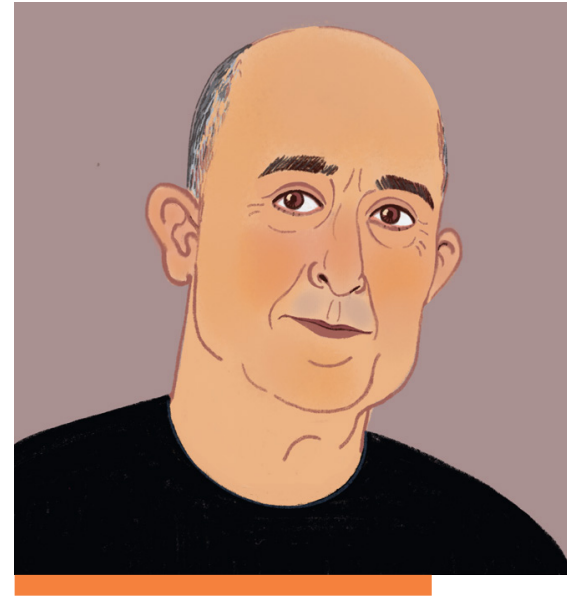

Cristóbal Gómez Mayorga

\section{RESUMEN}

Para innovar en la escuela es necesario previamente realizar un buen diagnóstico. Se hace imprescindible por tanto tener una visión holística del contexto político, social, económico y de las características del centro educativo y su entorno. De lo contrario podemos simplificar y malinterpretar las relaciones que se establecen en el aula.

Palabras clave: innovación educativa; evaluación contextual; relaciones de poder

\section{ABSTRACT}

In order to innovate in schools, it is first necessary to carry out a good diagnosis. It is therefore essential to have a holistic vision of the political, social and economic context and the characteristics of the school and its environment. Otherwise we can simplify and misinterpret the relationships established in the classroom.

Keywords: educational innovation; contextual assessment; power relationships

A menudo, en la escuela, sentimos que el alumnado nos hace la vida imposible: está quien se mueve demasiado y nos impide dar clase, quien interrumpe constantemente, quien habla con el de al lado, quienes no miran ni atienden, quien no puede y se distrae, quien no quiere y molesta... A veces, creemos que hay toda una conspiración en contra de las personas que nos dedicamos a enseñar.

Esta narración es una construcción exculpatoria que se extiende por todos los saraos educativos y que adoptamos cuando nos sentimos mal dando clase. Es un discurso re- 
currente que solemos repetir, quienes nos dedicamos a la educación, cuando sentimos que el alumnado se nos va de las manos. Pero la realidad es más compleja. Dice Humberto Maturana: Lo que usted oye de lo que yo digo tiene que ver con usted y no conmigo.

Quien se aburre en clase, o no se interesa por lo que explicamos, no quiere hacernos mal alguno, no debemos tomarlo como algo personal. Cientos de circunstancias condicionan a cada personita que habita el aula. Posiblemente tiene que ver con que la vida es muy difícil, la escuela no está a la altura y no comprendemos qué pasa.

Es necesario alzar la mirada y vernos en una organización hermética y anquilosada de la que no tenemos toda la responsabilidad. Ver solamente nuestra relación con el alumnado es una simplicidad. Estamos inmersos en un sistema muy complejo. Hagamos una apertura de mira.

Por encima de nuestra intervención con el alumnado está el aula, un nicho ecológico en donde se establecen unas relaciones de comunicación, de poder, con historias, de prescripciones, de aprendizajes, de emociones e intereses, que se ponen en juego y que, a veces, no llegamos a comprender.

Abrimos el enfoque y vemos el centro escolar, multiplicando la complejidad: sus rutinas, liturgias, relaciones entre el profesorado, direcciones evitando conflictos, presión o complicidad de las familias, inspecciones amenazantes y burocracia, mucha burocracia impidiendo dedicarnos a lo importante.

Seguimos abriendo el encuadre y la escuela se nos hace pequeña. Y vislumbramos entonces el barrio, el pueblo, el contexto social de donde viene el alumnado; con sus características sociales, económicas y culturales que influyen sobremanera en las relaciones de comunicación del aula. Cada cual, con su familia a cuesta, con sus miles de problemas y circunstancias concretas.

Seguimos abriendo el zoom y aparece la nacionalidad y el estado: con sus políticas educativas, titularidad de centros, presupuestos, lobbies editoriales, normativas y leyes.

Y por encima de todos los encuadres, un sistema económico determinante: economicista, competitivo, indivi- 


\section{"El cambio comienza con las relaciones que establecemos en el aula con nuestro alumnado."}

dualista y hedonista; que produce diferencias evidentes a las familias que tienen distintas posibilidades.

Es necesario aprender que nadie está en contra nuestra, y menos los niños y las niñas de la clase. Hay todo un sistema complejo que determina lo que pasa en la escuela. Es bueno saberlo para repartir culpabilidades. A más poder debemos otorgar mayor responsabilidad.

No obstante, hay algo que debemos hacer en el microcosmos en el que ejercemos como educadores: ser auténticos, porque eso enseñaremos; ser profesionales, porque ayudaremos a mejorar la sociedad; ser amorosos, porque educaremos en el amor a los demás; enseñar todo lo que sabemos de la mejor manera posible, porque haremos futuros ciudadanos que mejoren el mundo; $y$, por último, ser ético, porque contribuiremos a formar mejores personas.

El cambio comienza con las relaciones que establecemos en el aula con nuestro alumnado, pero siendo consciente de que todas las personas estamos determinados por el contexto. Y, a pesar de ello, debemos asumir la responsabilidad que nos toca, para ir, poco a poco, cambiando la escuela y, quién sabe si también, el mundo.

Por tanto, lo que pasa entre mi alumnado y yo no está sólo en mí, ni tampoco en las chicas y chicos del aula; hay, detrás, todo un mundo complejo conspirando. Y las responsabilidades hay que repartirlas en función del poder que cada cual ejerce. No echemos la culpa siempre al más débil del sistema. 